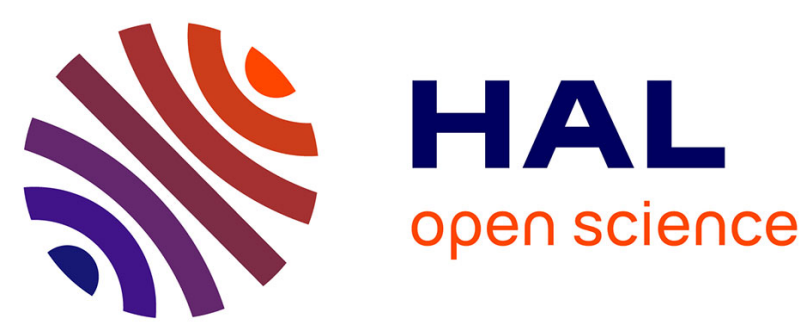

\title{
Comparison of Prognostic Usefulness of Serum Insulin-Like Growth Factor-Binding Protein 7 in Patients With Heart Failure and Preserved Versus Reduced Left Ventricular Ejection Fraction
}

Camilla Hage, Mette Bjerre, Jan Frystyk, Harvest F. Gu, Kerstin Brismar, Erwan Donal, Jean-Claude Daubert, Cecilia Linde, Lars H. Lund

\section{To cite this version:}

Camilla Hage, Mette Bjerre, Jan Frystyk, Harvest F. Gu, Kerstin Brismar, et al.. Comparison of Prognostic Usefulness of Serum Insulin-Like Growth Factor-Binding Protein 7 in Patients With Heart Failure and Preserved Versus Reduced Left Ventricular Ejection Fraction. American Journal of Cardiology, 2018, 121 (12), pp.1558-1566. 10.1016/j.amjcard.2018.02.041 . hal-01874526

HAL Id: hal-01874526

https://hal-univ-rennes1.archives-ouvertes.fr/hal-01874526

Submitted on 18 Sep 2018

HAL is a multi-disciplinary open access archive for the deposit and dissemination of scientific research documents, whether they are published or not. The documents may come from teaching and research institutions in France or abroad, or from public or private research centers.
L'archive ouverte pluridisciplinaire HAL, est destinée au dépôt et à la diffusion de documents scientifiques de niveau recherche, publiés ou non, émanant des établissements d'enseignement et de recherche français ou étrangers, des laboratoires publics ou privés. 


\section{Comparison of Prognostic Usefulness of Serum Insulin-like Growth Factor-binding Protein 7 in Patients with Heart Failure and Preserved versus Reduced Left Ventricular Ejection Fraction}

Camilla Hage RN, $\mathrm{PhD}^{\mathrm{a}}$, Mette Bjerre MD, PhD ${ }^{\mathrm{b}}$, Jan Frystyk MD, PhD ${ }^{\mathrm{b}}$, Harvest F. Gu MD, PhD ${ }^{\mathrm{c}}$, Kerstin Brismar MD, PhD ${ }^{d}$, Erwan Donal MD, PhD ${ }^{e}$, Jean-Claude Daubert MD ${ }^{e}, P h D$, Cecilia Linde MD, PhD ${ }^{a}$, Lars H. Lund MD, PhD ${ }^{\mathrm{a}}$

a) Karolinska Institutet, Department of Medicine, Cardiology unit, Stockholm, Sweden

b) Aarhus University, Department of Clinical Medicine, Medical Research Laboratory, Aarhus, Denmark

c) Karolinska Institutet, Department of Clinical Science, Intervention and Technology, Stockholm, Sweden

d) Karolinska Institutet, Department of Molecular Medicine and Surgery, Stockholm, Sweden

e) Département de Cardiologie \& CICIT1414 , Centre Hospitalier Universitaire de Rennes, Rennes, France

\section{GRANT SUPPORT}

The Karen study was partly supported by grants from Medtronic Bakken Research Center, Maastricht, The Netherlands and Fédération Française de Cardiologie/Société Française de Cardiologie, France. CH was supported by Center for Gender Medicine Karolinska Institutet, Stockholm Sweden. KB was supported by the Family Erling-Persson Foundation (KB) and the Swedish Research Council. CL was supported by the Swedish Heart Lung Foundation [grants 20080498 and 20110406] and the Stockholm County Council [grants 20090376 and 20110610]. LHL was supported by the Swedish Research Council [grant 2013-23897-104604-23] Swedish Heart Lung Foundation [grants 20080409 and 20100419] and the Stockholm County Council [grants 00556-2009 and 20110120]. No funding agency had any role in the design and conduct of the study, in the collection, management, analysis, or interpretation of the data.

Supplemental material:

Tables: 1

Figures: -

Address for correspondence:

Camilla Hage, RN, PhD

Department of Cardiology, Research Unit

Karolinska University Hospital

SE-171 76 Stockholm, Sweden

Telephone: +468517 79282

Fax number: +468344964

e-mail: camilla.hage@karolinska.se 


\section{ABSTRACT}

We aimed to characterize of the role of insulin-like growth factor-binding protein 7 (IGFBP-7) in heart failure (HF) pathophysiology. IGFBP-7 has been associated with cardiac hypertrophy and diastolic dysfunction in HF. In 86 patients with $\mathrm{HFpEF}$ ( $\mathrm{EF} \geq 45 \%$ ) and 79 with $\mathrm{HFrEF}$, we assessed concentrations of serum IGFBP-7, correlations between serum IGFBP-7 and clinical data, diastolic function and associations with outcome. IGFBP-7 was lower in HFpEF than HFrEF (102 vs. $152 \mathrm{ug} / \mathrm{L} ; p<0.001$ ) and correlated with NYHA class (HFpEF;r=0.25; $p=0.020$, HFrEF 0.26; $p=0.022$ ), NT-proBNP (HFpEF;r= 0.53; $p<0.001$, HFrEF; $r=0.50 ; p<0.001$ ) and eGFR (HFpEF; $r=-0.47 ; p<0.001$, HFrEF: $r=-0.45 ; p<0.001$ ). In HFpEF, IGFBP-7 correlated with $E / e^{\prime}(r=0.31 ; p=0.012)$ and E/A ratio $(r=0.31 ; p=0.011)$. In HFrEF, but not HFpEF, IGFBP-7 correlated with age $(r=0.29 ; p=0.009)$ and atrial fibrillation ( $r=0.34 ; p=0.002)$. IGFBP-7 predicted outcome in HFpEF (hazard ratio 4.19 [1.01-17.35], $p=0.048]$ ), but not HFrEF (0.72 [0.24-2.14], $p=0.554)$. In conclusion in HFrEF, IGFBP-7 was elevated and associated with HF severity but not prognostic, suggesting a marker of risk. In HFpEF, IGFBP-7 was less elevated but associated with markers of diastolic dysfunction, HF severity, and prognosis, IGFBP-7 may contribute to progression of HFpEF possibly through inflammation and oxidative stress.

Clinical Trial Registration: ClinicalTrials.gov NCT00774709 https://clinicaltrials.gov

Key words: HFpEF, diastolic dysfunction, IGFBP-7, prognosis 


\section{INTRODUCTION}

Patients with heart failure (HF) is associated with reduced left ventricular ejection fraction (LVEF <40\%; HFrEF) or preserved LVEF ( $\geq 50 \%$; HFpEF). The HFpEF syndrome is as common and associated with nearly the same rates of overall mortality as $\operatorname{HFrEF}(1)$ but more complex and there are no approved therapies $(2,3)$ suggesting distinct different underlying pathophysiologies (4). A new paradigm presents HFpEF as a heterogeneous comorbidity-driven global inflammatory syndrome, initiated by conditions such as diabetes and other co-morbidities (5). The chain of events includes inflammation, increased reactive oxygen species (ROS) production, coronary microvascular endothelial dysfunction leading to cardiomyocyte stiffness, cellular hypertrophy and increased myocardial fibrosis (6). In accordance we have demonstrated the importance of upregulated inflammatory pathways, and a downregulation of apoptosis in patients with HFpEF (7)(8). The insulin-like growth factor binding protein 7 (IGFBP-7), also called IGFBP-related protein-1 or angiomodulin, is a secretory glycoprotein expressed in various tissues including the heart, vascular endothelial cells, and fibroblasts (9). IGFBP-7 binds to insulin-like growth factor-I (IGF-I) (10), but with much less affinity than IGFBP-1 to -6 and regulate of a number of pathophysiological conditions including cell death and early effects of insulin action (9) processes involved in insulin resistance and type 2 diabetes (T2D), inflammation and endothelial dysfunction, all potential drivers of HFpEF (11). Elevated serum IGFBP-7 are in both HFpEF and HFrEF patients associated with abnormal diastolic function (12) (13), and suggested to be linked to cardiac hypertrophy (14) and cardiovascular events $(15,16)$. In HFpEF patients, IGFBP-7 has primarily been assessed in clinical trials populations such as I-PRESERVE (15) and RELAX (12). We aimed to further characterize the role of IGFBP-7 in HF pathophysiology by 1) measuring serum IGFBP-7 in patients with HFrEF prior to and after implantation of left ventricular assist device (LVAD) and/or heart transplantation (HTx); 2) correlating IGFBP-7 with echocardiographic variables and emerging biomarkers in the KaRen HFpEF cohort (17); and 3) investigating associations with the prognosis of patients suffering from HFpEF or HFrEF.

\section{METHODS}

Patients with HFpEF were recruited from the Karolinska Rennes (KaRen) prospective observational multicenter study characterizing patients with HFpEF, as described in detail elsewhere (17). In brief, 539 patients presenting to hospital with acute signs and symptoms of HF according to the Framingham criteria, N-terminal pro-brain natriuretic peptide (NT-proBNP) >300 ng/L and a left ventricular ejection fraction (LVEF) $\geq 45 \%$ assessed within 72 hours from presentation, were enrolled in French and Swedish centers. The pre-specified biomarker sub-study enrolled 86 patients 
between 21 of May 2007 - 29 of December 2011 at Karolinska University Hospital, Stockholm, Sweden. Patients returned to the hospital in stable condition 4-8 weeks after enrolment (baseline in the present analysis) for a follow-up visit including blood sampling and detailed echocardiography and followed until 30 September 2012 when vital status was assessed by telephone contact or by the Swedish National Patient Register and Population Register. The primary composite endpoint was defined as time to death from any cause or first hospitalization due to HF. All HF hospitalizations defined according to clinical judgment by the local investigator and additionally centrality adjudicated.

Patients with HFrEF ( $n=79)$ were enrolled in the MetAnEnd study recruiting patients with LVEF $<40 \%$, referred to the Karolinska University Hospital for advanced HF assessment between January 2009 and September 2014 (18). Blood sampling was performed prior LVAD implantations and/or HTx. The primary composite endpoint was death from any cause, implantation of LVAD or HTx. Vital status was assessed by the Swedish National Patient and Population Registers and implantation of LVAD or HTx by patient charts in December 2014.

Within the MetAnEnd study blood sampling was performed at baseline, post LVAD and post HTx however due to small sample size in complete serial measurements data was analyzed as cross sectional (Figure 1). Blood samples were collected in 22 patients 1 year post LVAD implantation whereof 7 patients had blood sampled at 2 serial occasions; prior to intervention and 1 year post LVAD implantation. In 34 patients blood samples were collected 1 year post HTx, whereof 17 patients were blood sampled prior to intervention and 1 year post HTx and 8 patients 1 year post LVAD implantation and 1 year post HTx.

The echocardiographic assessment was performed on a ViVid 7 echo-platform (GE VingMed, Horten, Norway) and analyzed in a dedicated core center in Hôpital Pontchaillou, Rennes, France. Each examination was interpreted once and measurements were performed 3 times and averaged by an echocardiographist (ED) blinded to the specific clinical history of the patient. Left ventricular hypertrophy (LVH) was defined as left ventricular mass index (LVMI) $\geq 95 \mathrm{~g} / \mathrm{m}^{2}$ in women and $\geq 115 \mathrm{~g} / \mathrm{m}^{2}$ in men, respectively (3).

At the follow-up visit blood samples were collected in a fasting state in the morning in serum tubes, centrifuged and plasma was aliquoted and stored in $-70^{\circ} \mathrm{C}$ until analysis. Serum IGFBP-7 levels were quantified by commercially available antibodies (from RnD Systems, DY1334) modified to time-resolved immunofluorometric assay (TR-IFMA). The limit of detection was $0.04 \mu \mathrm{g} / \mathrm{L}$. The inter- and intra-assay coefficients of variation were $\leq 8 \%$ and $\leq 5 \%$. Estimated glomerular filtration rate (eGFR) was calculated according to the Modification of Diet in Renal Disease (MDRD) equation. 
NT-proBNP was analyzed by proBNPII (Roche Diagnostics, Bromma, Sweden). Leptin and adiponectin were analyzed with radio immunoassay (RIA) Merk Millipore ${ }^{\circledR}$ (HL-81 K and HADP-61 K). Serum IGF-I and IGFBP-1 were determined by inhouse RIAs. IGF-I values were expressed as age adjusted standard deviation (SD) scores calculated from the regression of the IGF-I concentrations of healthy adult subjects (SD score=((10InIGF-I-observed+0.00693*age)-2.581)/0.120) (19). Insulin was analyzed with ELISA K6219 (Dako cytomation, Stockolm, Sweden). Insulin resistance was assessed according to homeostatic model assessment (HOMA-IR) calculated as ([glucose*Insulin]/22.5; with glucose in mmol/L and insulin in $\mathrm{mU} / \mathrm{L})$.

Descriptive data in Table 1 is expressed as median and quartiles (Q1;Q3) or number (\%) and compared by the Wilcoxon rank sum test and Fisher's exact test when comparing HFpEF vs. HFrEF and Kruskal-Wallis test and Chi-square when comparing differences between HFrEF, LVAD and HTx. The difference in IGFBP-7 concentrations between HF groups and NYHA classes was determined by ANOVA (unadjusted) and ANCOVA adjusted for eGFR and NT-proBNP. Bivariate correlations with plasma or serum biomarkers, echocardiographic and clinical variables were established by Spearman and multiple analyses by linear and logistic regression analyses. Associations with outcome were determined with KaplanMeier and Cox proportional hazards models, the latter presented as hazard ratio (HR) and 95\% confidence interval (Cl). In the final multivariable Cox regression model 4 clinically significant covariates, age, sex, eGFR and NT-proBNP were included. Due to non-normal distribution biomarkers were analyzed in log-transformed format. P-values were 2-sided and statistical significance was set at 0.05. Statistical analyses were performed using SAS software version 9.3 (SAS Institute, Cary N.C, USA).

The KaRen and MetAnEnd studies were conducted according to International Conference on Harmonization and Good Clinical Practice guidelines and the Declaration of Helsinki and the study was approved by the ethical review board at Karolinska Institutet. Written informed consent was obtained from all patients.

\section{RESULTS}

Characteristics of the $86 \mathrm{HFpEF}$ and $79 \mathrm{HFrEF}$ patients are presented in Table 1. Twenty-three percent of the HFpEF patients had E/e' $>15,67 \%$ had $e^{\prime}<9,89 \%$ had LAVI $>34 \mathrm{ml} / \mathrm{m}^{2}$ and $61 \%$ fulfilled criteria for LVH. Among HFrEF patients $46 \%$ had dilated cardiomyopathy, $39 \%$ had HF of ischemic etiology, $3 \%$ congenital and $4 \%$ infiltrative heart disease, $2 \%$ giant cell myocarditis and $2 \%$ postpartum cardiomyopathy. Patient characteristics of the 22 LVAD and 34 HTX patients are presented in Supplementary Table. 
The concentration of IGFBP-7 was lower in HFpEF, 102 [85-128] ug/L compared to HFrEF, 152 [120-206] ug/L, (pvalue $<0.001$ ) and decreased in HFrEF after LVAD treatment, 126 ug/L [102-148] and HTx, 101 [87-110] ug/L (overall pvalue $<0.001$; Figure 2). When adjusted for NT-proBNP and eGFR, the difference remained significant when comparing HFpEF and HFrEF before ( $p$-values <0.001) but not after interventions, HFrEF and LVAD ( $p$-value=0.496) and LVAD and HTx (p-value=0.599). Similar concentrations of IGFBP-7 were found in males and females in both HFpEF, 100 [82-130] and 107 [87-128] ug/L ( p-value=0.773) respectively and HFrEF, 162 [123-213] ug/L and 146 [ 94-159] ug/L (p-value=0.124).

In unadjusted analyses in HFpEF and HFrEF, the concentrations of IGFBP-7 correlated modestly with NYHA class $(r=0.25 ; p$-value $=0.020$ and $r=0.26 ; p$-value 0.022 , respectively), however concentrations did not differ significantly between NYHA classes when adjusted for eGFR and NT-proBNP (Figure 3). As displayed in Table 2, multivariable analyses in HFpEF demonstrated weak to modest correlations between IGFBP-7 and T2D and history of cancer as well as glucose, eGFR, NT-proBNP, suppression of tumorigenicity 2 (ST2), MR-pro-adrenomedullin (MR-proADM) and MR-pro-atrial natriuretic peptide (MR-proANP). Also in HFrEF IGFBP-7 correlated weakly to modestly with eGFR, NT-proBNP, ST2, leptin, galectin-3 and IGFBP-1 and strongly with MR-proADM. In HFpEF serum IGFBP-7 correlated modestly with diastolic dysfunction assessed as $E / e^{\prime}(\beta$-coefficient $=0.438 ; p=0.004)$ but not with measurements of structural heart disease as LVMI and LAVI (Table 3).

Median follow-up time was in HFpEF and HFrEF patients 522 [238-1089] days and 217 [74-459] days respectively. No patients were lost during follow-up. In HFpEF the composite endpoint of death and HF hospitalization occurred in 36 patients, whereof 6 were death and in HFrEF patients, the composite endpoint of death, LVAD implantation or HTx occurred in 50 patients, including 27 deaths. Kaplan-Meier curves presenting the prognostic impact of IGFBP-7 are depicted in Figure 4. In HFpEF serum IGFBP-7 concentrations above median was associated with the composite outcome in unadjusted analysis (log-rank $p=0.002$ ) and as a continuous variable adjusted for eGFR, age, gender and NT-proBNP (HR 4.19 (95\% Cl 1.01-17.35; p-value=0.048). In contrast serum IGFBP-7 concentrations was not a prognostic predictor in patients with HFrEF, neither in univariate (HR 1.39 (95\% Cl 0.61-3.14; p-value=0.433) nor in multivariable analyses (HR $0.72(95 \% \mathrm{Cl} 0.24-2.14 ; \mathrm{p}$-value=0.554).

\section{DISCUSSION}

In HFrEF, serum IGFBP-7 was elevated compared to HFpEF, declining after LVAD and HTx and was associated with HF severity and kidney function. However, serum IGFBP-7 was not associated with the prognosis, thereby suggesting more 
of a role as risk marker and less a risk factor. In HFpEF, serum IGFBP-7 was less elevated but associated with diastolic dysfunction, HF severity and prognosis, indicating that IGFBP-7 may interact in the progression of the HFpEF syndrome, possibly through inflammation and oxidative stress.

Increased concentrations of IGFBP-7 have previously been demonstrated in patients with HFrEF and NYHA class III-IV (14) compared to controls. We show, to our knowledge for the first time, that high IGFBP-7 concentrations decreased after LVAD and HTx in HFrEF patients with advanced HF, predominately in NYHA class III, indicating that a decrease in IGFBP-7 reflects improvement in HF severity. The correlation with NYHA class was attenuated when adjusted for renal function and NT-proBNP suggesting that in HFrEF, IGFBP-7 reflects improvement in these parameters after intervention.

In HFpEF patients IGFBP-7 is elevated compared to patients with asymptomatic diastolic dysfunction and controls (20). We add to this spectrum by demonstrating lower levels in HFpEF compared to HFrEF. In concordance with previous data in HFpEF (12), IGFBP-7 was in both HFpEF and HFrEF correlated with a worse renal function expressed as eGFR and with increased NT-proBNP. The HFrEF patients had higher NT-proBNP and lower eGFR (57 vs. $70 \mathrm{ml} / \mathrm{min} / 1.73 \mathrm{~m}^{2}$ ), which to some extent may be associated with the increased IGFBP-7, however when adjusted for these parameters the difference between the $2 \mathrm{HF}$ groups remained statistically significant. Urinary IGFBP-7, along with TIMP-2, has in acute decompensated HF been suggested as a cell cycle arrest marker indicative of acute kidney injury (21). Cell cycle arrest is believed to be a protective mechanism initiated in the earliest stages of tubule cell stress/injury in response to insults, such as inflammation and oxidative stress, shutting down cell processes thereby protecting the cell from permanent damage or death.

We speculate that IGFBP-7 in HFpEF may in part reflect kidney injury initiated by comorbidity-driven oxidative stress which is suggested to be a driver of the HFpEF syndrome (6), while in HFrEF the increased IGFBP-7 concentrations reflect subsequent kidney damage following inflammation and oxidative stress induced by the HF disease itself. This is supported by decreasing concentrations of IGFBP-7 after intervention and the age and NT-proBNP adjusted correlation between eGFR and IGFBP-7.

IGFBP-7's relatively weak binding affinity to IGF-I and high affinity to insulin (9) compete with insulin receptors for insulin binding and interfere with the physiological response to insulin which may contribute to insulin resistance and to development of T2D. In fact, elevated concentrations of IGFBP-7 have been associated with the metabolic syndrome and insulin resistance (22). In our patients with HFpEF we could confirm a weak but still independent correlation with T2D and 
increasing glucose levels while this was not the case in HFrEF indicating a different role of IGFBP-7 and glucose-insulin homeostasis in the two HF phenotypes. Interestingly in patients with diabetes, IGFBP-7 indicate diastolic dysfunction prior to evident development of HF symptoms $(20,23)$ proposing that it may be associated with HFpEF disease progression.

Also, displaying a discrepant metabolic pattern in HFpEF and HFrEF was the correlation between serum IGFBP-7 and the adipocyte-derived hormone leptin (24) negatively correlated with IGFBP-7 in HFrEF but not in HFpEF. Leptin is associated with features of the metabolic syndrome such as obesity, insulin resistance and low-graded systemic inflammation contributing to leptin resistance, endothelial dysfunction and oxidative stress. In HFrEF leptin has been associated with the obesity paradox, perhaps linked to a catabolic state and displaying increased levels, a negative correlation with NT-proBNP and an association with improved prognosis (19). This was also indicated by the weak inverse correlation between leptin and IGFBP-7 in the present study.

Inflammation and oxidative stress are major components in all patients with HF regardless of LVEF however, their role in disease development of HFrEF and HFpEF may differ. In HFrEF inflammation is present as a result of a cell injury, while in HFpEF a systemic and microvascular endothelial inflammation is suggested to drive the disease $(5,6)$. In $\mathrm{HFpEF}$ accompanying comorbidities such as T2D contribute to oxidative stress through chronic mitochondrial overproduction of ROS which occurs by several mechanisms, such as formation of advanced glycation end products (AGEs) and xanthine oxidoreductase and nicotinamide adenine dinucleotide phosphate (NADPH) oxidase. This leads to an endothelial inflammation $(5,11)$ which induce endothelial-mesenchymal transition, when endothelial cells turn into fibroblasts, which has been suggested to drive the development of diastolic dysfunction and disease development in $\operatorname{HFpEF}(5,7)$. IGFBP-7 is induced in endothelial cells by the pro-inflammatory cytokine TNF- $\alpha(25)$ and may also activate normal fibroblasts through TGF $\beta$ related mechanisms (26). Thus, IGFBP-7 could be linked to fibrosis and progression of diastolic dysfunction through endothelial inflammation and oxidative stress. Supportive of this, IGFBP-7 in our HFpEF patients correlated with fibrotic markers such as ST2 and galectin-3 and also with diastolic dysfunction as demonstrated by E/e'. In HFrEF patients enrolled in the PROTECT study a cutoff level of IGFBP-7 >117.8 ug/L was identified as predictive of cardiovascular events (16). This is in contrast to our findings where IGFBP-7 was not a prognostic predictor as a continuous variable (direct comparison in cutoff difficult due to the use of different assays). The discrepancy may be due to the difference in endpoints as we did not include cardiovascular events. Furthermore, PROTECT included stable out-patients with NT-proBNP of $2118 \mathrm{ng} / \mathrm{L}$ compared to our HFrEF patients assessed for advanced HF treatment with higher NT-proBNP 
$3425 \mathrm{ng} / \mathrm{L}$. It may be that in a HF population with a more advanced HF disease the independent prognostic information from IGFBP-7 is less prominent. IGFBP-7 has been suggested as a tumor-suppressing protein as it binds to the IGF-1 and insulin receptors suppressing downstream signaling thereby inhibiting cell growth and promoting apoptosis (10). However also high expression has been associated with cancer (26), a correlation also found in the present HFpEF population. IGFBP-7 may have IGF and insulin independent effects via binding to other receptors, like the other binding proteins (27). Further we could confirm IGFBP-7 as an independent prognostic predictor in HFpEF in accordance with recent reports (15). In HFpEF we have previously demonstrated a downregulation of apoptosis as a prognostic predictor in HFpEF (7), which is supported by the higher IGF-I levels (18), thus IGFBP-7 suggested properties to stimulate growth of fibroblasts and fibrosis may contribute to disease progression in HFpEF.

The HFpEF diagnosis in KaRen did not require echocardiographic verification as recommended by ESC guidelines (LVEF $\geq 50 \%$ ) (3). However, the inclusion criteria, including NT-proBNP $>300 \mathrm{ng} / \mathrm{L}$ and LVEF $\geq 45 \%$, were similar to other HFpEF trials at the time and the HF diagnosis was verified by Framingham criteria $(28,29)$. The HFpEF and HFrEF patients were collected separately to study phenotypes (eg. not matched) wherefore some characteristic features such as age and heart failure severity differ. Trying to account for these differences, we have included variables such as age, eGFR, NTproBNP and weight in the multivariable regression analyses when comparing concentrations between groups. Further inflammatory biomarkers would indeed be of interest and have been analyzed in the HFpEF cohort but not in the HFrEF/LVAD/HTx patients why we chose not to include these data. The small sample size is a limitation and it is important to further study IGFBP-7 as a prognostic marker in larger patient materials.

In conclusion serum IGFBP-7 was elevated in HFrEF, declining after LVAD and further after heart transplant. In HFrEF, concentrations of IGFBP-7 were associated with HF severity and kidney function but not prognostic, suggesting more of a risk marker role rather than a risk factor. In HFpEF, serum IGFBP-7 was less elevated but associated with severity of HF, diastolic dysfunction and markers of fibrosis and oxidative stress and independently with prognosis.

\section{ACKNOWLEDGMENTS}

The authors are grateful to Susanne Sørensen for IGFBP-7 analyses and Gunilla Förstedt, Kambiz Shahgaldi, Maria Westerlind, Anette Landström, Elisabeth Krogh-Noren and Eva Wallgren for echocardiogram and laboratory analysis. 


\section{DISCLOSURES}

$\mathrm{CH}$ : consulting fees from Novartis and speaker and honoraria from MSD; LHL: research grants and speaker and honoraria from AstraZeneca, Novartis, St Jude Medical and Boston Scientific; CL: research grants, speaker honoraria and consulting fees from Medtronic and St. Jude Medical; ED: speaker honoraria and consulting fees from Novartis, AstraZeneca; JCD: research grants, speaker honoraria and consulting fees from Medtronic and St Jude Medical. The authors had full access to all the data in the study and take responsibility for its integrity and the data analysis. All authors have participated in the work and have reviewed and agree with the content of the article.

1) conception and design or analysis and interpretation of data, or both; 2) drafting of the manuscript or revising it critically for important intellectual content; 3) final approval of the manuscript submitted None of the article contents are under consideration for publication in any other journal or have been published in any journal and no portion of the text has been copied from other material in the literature. 


\section{REFERENCES}

1. Chan MM, Lam CS. How do patients with heart failure with preserved ejection fraction die? Eur J Heart Fail 2013;15:604-613.

2. Butler J, Fonarow GC, Zile MR, Lam CS, Roessig L, Schelbert EB, Shah SJ, Ahmed A, Bonow RO, Cleland JG, Cody RJ, Chioncel O, Collins SP, Dunnmon P, Filippatos G, Lefkowitz MP, Marti CN, McMurray JJ, Misselwitz F, Nodari S, O'Connor C, Pfeffer MA, Pieske B, Pitt B, Rosano G, Sabbah HN, Senni M, Solomon SD, Stockbridge N, Teerlink JR, Georgiopoulou VV, Gheorghiade M. Developing Therapies for Heart Failure With Preserved Ejection Fraction: Current State and Future Directions. JACC Heart Fail 2014;2:97-112.

3. Ponikowski P, Voors AA, Anker SD, Bueno H, Cleland JGF, Coats AJS, Falk V, González-Juanatey JR, Harjola V-P, Jankowska EA, Jessup M, Linde C, Nihoyannopoulos P, Parissis JT, Pieske B, Riley JP, Rosano GMC, Ruilope LM, Ruschitzka F, Rutten FH, van der Meer P. 2016 ESC Guidelines for the diagnosis and treatment of acute and chronic heart failure. Eur J Heart Fail 2016;18:891-975.

4. Lund LH, Donal E, Oger E, Hage C, Persson H, Haugen-Lofman I, Ennezat PV, Sportouch-Dukhan C, Drouet E, Daubert JC, Linde C. Association between cardiovascular vs. non-cardiovascular co-morbidities and outcomes in heart failure with preserved ejection fraction. Eur J Heart Fail 2014;16:992-1001.

5. Lam CS, Lund LH. Microvascular endothelial dysfunction in heart failure with preserved ejection fraction. Heart 2016;102:257-259. doi: 210.1136/heartjnl-2015-308852.

6. Paulus WJ, Tschope C. A novel paradigm for heart failure with preserved ejection fraction: comorbidities drive myocardial dysfunction and remodeling through coronary microvascular endothelial inflammation. J Am Coll Cardiol 2013;62:263-271.

7. Hage C, Michaelsson E, Linde C, Donal E, Daubert JC, Gan LM, Lund LH. Inflammatory Biomarkers Predict Heart Failure Severity and Prognosis in Patients With Heart Failure With Preserved Ejection Fraction: A Holistic Proteomic Approach. Circ Cardiovasc Genet 2017;10(1).e001633. doi: 001610.001161/CIRCGENETICS.001116.001633.

8. Donal E, Lund LH, Oger E, Hage C, Persson H, Reynaud A, Ennezat PV, Bauer F, Sportouch-Dukhan C, Drouet E, Daubert JC, Linde C. Baseline characteristics of patients with heart failure and preserved ejection fraction included in the Karolinska Rennes (KaRen) study. Arch Cardiovasc Dis 2014;107:112-121. 
9. Oh Y, Nagalla SR, Yamanaka Y, Kim HS, Wilson E, Rosenfeld RG. Synthesis and characterization of insulin-like growth factor-binding protein (IGFBP)-7. Recombinant human mac25 protein specifically binds IGF-I and -II. J Biol Chem $1996 ; 271: 30322-30325$.

10. Evdokimova V, Tognon CE, Benatar T, Yang W, Krutikov K, Pollak M, Sorensen PH, Seth A. IGFBP7 binds to the IGF1 receptor and blocks its activation by insulin-like growth factors. Sci Signal 2012;5:ra92. doi: 10.1126/scisignal.2003184. 11. Joshi M, Kotha SR, Malireddy S, Selvaraju V, Satoskar AR, Palesty A, McFadden DW, Parinandi NL, Maulik N. Conundrum of pathogenesis of diabetic cardiomyopathy: role of vascular endothelial dysfunction, reactive oxygen species, and mitochondria. Mol Cell Biochem 2014;386:233-249.

12. Gandhi PU, Gaggin HK, Redfield MM, Chen HH, Stevens SR, Anstrom KJ, Semigran MJ, Liu P, Januzzi JL, Jr. InsulinLike Growth Factor-Binding Protein-7 as a Biomarker of Diastolic Dysfunction and Functional Capacity in Heart Failure With Preserved Ejection Fraction: Results From the RELAX Trial. JACC Heart Fail 2016;4:860-869.

13. Gandhi PU, Gaggin HK, Sheftel AD, Belcher AM, Weiner RB, Baggish AL, Motiwala SR, Liu PP, Januzzi JL, Jr. Prognostic usefulness of insulin-like growth factor-binding protein 7 in heart failure with reduced ejection fraction: a novel biomarker of myocardial diastolic function? Am J Cardiol 2014;114:1543-1549.

14. Chugh S, Ouzounian M, Lu Z, Mohamed S, Li W, Bousette N, Liu PP, Gramolini AO. Pilot study identifying myosin heavy chain 7, desmin, insulin-like growth factor 7, and annexin A2 as circulating biomarkers of human heart failure.

\section{Proteomics 2013;13:2324-2334.}

15. Gandhi PU, Chow SL, Rector TS, Krum H, Gaggin HK, McMurray JJ, Zile MR, Komajda M, McKelvie RS, Carson PE, Januzzi JL, Jr., Anand IS. Prognostic Value of Insulin-Like Growth Factor-Binding Protein 7 in Patients with Heart Failure and Preserved Ejection Fraction. J Card Fail 2017;23:20-28.

16. Motiwala SR, Szymonifka J, Belcher A, Weiner RB, Baggish AL, Gaggin HK, Bhardwaj A, Januzzi JL, Jr. Measurement of novel biomarkers to predict chronic heart failure outcomes and left ventricular remodeling. J Cardiovasc Trans/ Res $2014 ; 7: 250-261$

17. Donal E, Lund LH, Linde C, Edner M, Lafitte S, Persson H, Bauer F, Ohrvik J, Ennezat PV, Hage C, Lofman I, Juilliere Y, Logeart D, Derumeaux G, Gueret P, Daubert JC. Rationale and design of the Karolinska-Rennes (KaRen) prospective study of dyssynchrony in heart failure with preserved ejection fraction. Eur J Heart Fail 2009;11:198-204. 
18. Faxen UL, Hage C, Benson L, Zabarovskaja S, Andreasson A, Donal E, Daubert JC, Linde C, Brismar K, Lund LH. HFpEF and HFrEF Display Different Phenotypes as Assessed by IGF-1 and IGFBP-1. J Card Fail 2017;23:293-303. doi: 210.1016/j.cardfail.2016.1006.1008. Epub 2016 Jun 1017.

19. Faxen UL, Hage C, Andreasson A, Donal E, Daubert JC, Linde C, Brismar K, Lund LH. HFpEF and HFrEF exhibit different phenotypes as assessed by leptin and adiponectin. Int J Cardiol 2017;228:709-716.

20. Barroso MC, Kramer F, Greene SJ, Scheyer D, Kohler T, Karoff M, Seyfarth M, Gheorghiade M, Dinh W. Serum insulin-like growth factor-1 and its binding protein-7: potential novel biomarkers for heart failure with preserved ejection fraction. BMC Cardiovasc Disord 2016;16:199.

21. Schanz M, Shi J, Wasser C, Alscher MD, Kimmel M. Urinary [TIMP-2] x [IGFBP7] for risk prediction of acute kidney injury in decompensated heart failure. Clin Cardiol 2017;40:485-491. doi: 410.1002/clc.22683. Epub 22017 Mar 22610.

22. Liu Y, Wu M, Ling J, Cai L, Zhang D, Gu HF, Wang H, Zhu Y, Lai M. Serum IGFBP7 levels associate with insulin resistance and the risk of metabolic syndrome in a Chinese population. Sci Rep 2015;5:10227.

23. Shaver A, Nichols A, Thompson E, Mallick A, Payne K, Jones C, Manne ND, Sundaram S, Shapiro JI, Sodhi K. Role of Serum Biomarkers in Early Detection of Diabetic Cardiomyopathy in the West Virginian Population. Int J Med Sci 2016;13:161-168.

24. Zeidan A, Karmazyn M. Leptin and vascular smooth muscle. Curr Vasc Pharmacol 2006;4:383-393.

25. Usui T, Murai T, Tanaka T, Yamaguchi K, Nagakubo D, Lee CM, Kiyomi M, Tamura S, Matsuzawa Y, Miyasaka M. Characterization of mac25/angiomodulin expression by high endothelial venule cells in lymphoid tissues and its identification as an inducible marker for activated endothelial cells. Int Immunol 2002;14:1273-1282.

26. Komiya E, Furuya M, Watanabe N, Miyagi Y, Higashi S, Miyazaki K. Elevated expression of angiomodulin (AGM/IGFBP-rP1) in tumor stroma and its roles in fibroblast activation. Cancer Sci 2012;103:691-699.

27. Verhagen HJ, de Leeuw DC, Roemer MG, Denkers F, Pouwels W, Rutten A, Celie PH, Ossenkoppele GJ, Schuurhuis GJ, Smit L. IGFBP7 induces apoptosis of acute myeloid leukemia cells and synergizes with chemotherapy in suppression of leukemia cell survival. Cell Death Dis 2014;5:e1300.

28. Pitt B, Pfeffer MA, Assmann SF, Boineau R, Anand IS, Claggett B, Clausell N, Desai AS, Diaz R, Fleg JL, Gordeev I, Harty B, Heitner JF, Kenwood CT, Lewis EF, O'Meara E, Probstfield JL, Shaburishvili T, Shah SJ, Solomon SD, Sweitzer NK, Yang S, McKinlay SM. Spironolactone for heart failure with preserved ejection fraction. N Engl J Med 2014;370:1383-1392. 
29. Massie BM, Carson PE, McMurray JJ, Komajda M, McKelvie R, Zile MR, Anderson S, Donovan M, Iverson E, Staiger C, Ptaszynska A. Irbesartan in patients with heart failure and preserved ejection fraction. N Engl J Med 2008;359:24562467. doi: 2410.1056/NEJMoa0805450. Epub 0802008 Nov 0805411. 


\section{FIGURE LEGENDS}

Figure 1. Flow chart of enrolled patients with HFrEF. Shaded boxes indicated number of patients with blood sampled before and 1 year after intervention. None of the patients were blood sampled at 3 occasions.

Figure 2. Log IGFBP-7 in HFpEF, HFrEF, post LVAD and post HTx.

Figure 3. Log IGFBP-7 in HFpEF and HFrEF by NYHA class adjusted eGFR and NT-proBNP.

Figure 4. Association between IGFBP-7 above and below median and log IGFBP-7 as a continuous variable in Cox regression analyses and the composite outcome in HFpEF and HFrEF. 
Table 1. Baseline characteristics in the $86 \mathrm{HFpEF}$ and $79 \mathrm{HFrEF}$ patients. Continuous variables are presented as median and lower and upper quartiles $(\mathrm{Q} 1 ; \mathrm{Q} 3)$ and categorical variables as numbers $(\mathrm{n})$ and percentages when not otherwise stated.

\begin{tabular}{|c|c|c|c|}
\hline Variable & HFpEF & HFrEF & \\
\hline & $(n=86)$ & $(n=79)$ & p-value \\
\hline Age; median (Q1;Q3) (years) & $73(67 ; 79)$ & $64(52 ; 69)$ & $<0.001$ \\
\hline Women & $44(51 \%)$ & $13(16 \%)$ & $<0.001$ \\
\hline Chronic Obstructive Pulmonary Disease & $17(20 \%)$ & $10(13 \%)$ & 0.293 \\
\hline Diabetes Mellitus type 2 & $28(33 \%)$ & $24(30 \%)$ & 0.867 \\
\hline Cancer & $15(17 \%)$ & $7(9 \%)$ & 0.115 \\
\hline Hypertension & $68(79 \%)$ & - & \\
\hline Atrial fibrillation/flutter & $52(60 \%)$ & $40(51 \%)$ & 0.214 \\
\hline Coronary artery disease & $29(34 \%)$ & $36(46 \%)$ & 0.151 \\
\hline Whereof revascularized & $17(59 \%)$ & $30(79 \%)$ & $<0.001$ \\
\hline Revascularized & $17(20 \%)$ & $30(38 \%)$ & 0.015 \\
\hline NYHA class I & $19(22 \%)$ & $1(1 \%)$ & \\
\hline class II & $47(55 \%)$ & $4(5 \%)$ & $<0.001$ \\
\hline class III & $20(23 \%)$ & $65(82 \%)$ & \\
\hline class IV & $0(0 \%)$ & 9 (11\%) & \\
\hline
\end{tabular}




\begin{tabular}{|c|c|c|c|}
\hline Weight (kg) & $83(72 ; 98)$ & $85(72 ; 96)$ & 0.829 \\
\hline Body Mass Index $\left(\mathrm{kg} / \mathrm{m}^{2}\right)$ & $28.5(25.0 ; 32.9)$ & $27.5(23.2 ; 30.0)$ & 0.033 \\
\hline Systolic blood pressure (mmHg) & $140(130 ; 150)$ & $108(96 ; 122)$ & $<0.001$ \\
\hline Diastolic blood pressure (mmHg) & $80(70 ; 85)$ & $70(62 ; 80)$ & $<0.001$ \\
\hline Heart rate (beats/min) & $70(51 ; 92)$ & $70(60 ; 75)$ & 0.435 \\
\hline Angiotensin II receptor blocker & $28(33 \%)$ & $28(35 \%)$ & 0.744 \\
\hline Angiotensin converting enzyme inhibitor & $42(49 \%)$ & $48(61 \%)$ & 0.159 \\
\hline Beta blocker & $69(80 \%)$ & $78(99 \%)$ & $<0.001$ \\
\hline Tiazid diuretics & $14(16 \%)$ & - & \\
\hline
\end{tabular}

diuretics

\begin{tabular}{|c|c|c|c|}
\hline Loop diuretics & $61(71 \%)$ & 69 (87\%) & 0.013 \\
\hline Calcium channel blocker & $27(31 \%)$ & $2(3 \%)$ & $<0.001$ \\
\hline Anticoagulants & $47(55 \%)$ & $48(61 \%)$ & 0.436 \\
\hline Antiplatelet & $29(34 \%)$ & $22(28 \%)$ & 0.500 \\
\hline Statins & $38(44 \%)$ & $35(44 \%)$ & 1.000 \\
\hline Left Ventricular Ejection Fraction (\%) & $64(58 ; 68)$ & $22(15 ; 28)$ & $<0.001$ \\
\hline
\end{tabular}


Left Ventricular End Diastolic diameter ( $\mathrm{mm}$ )

Left Atrial Volume Index $\left(\mathrm{mL} / \mathrm{m}^{2}\right)$

Left ventricular mass index $\left(\mathrm{g} / \mathrm{m}^{2}\right)$

men

women

\section{E/A ratio}

E/e' ratio

$E^{\prime}$

Isovolumic Relaxation Time (diastole)

Mitral Velocity-Time Integral

E-wave deceleration time (ms)

$203(156 ; 228)$

$44(38 ; 52)$

$114(95 ; 143)$

$125(102 ; 157)$

$109(94 ; 136)$

$1.3(0.9 ; 2.1)$

$10.8(8.3 ; 14.0)$

$8.0(7.0 ; 10.0)$

$94(77 ; 113)$

$23(16 ; 30)$

$47(43 ; 53) \quad 66(61 ; 75) \quad<0.001$ 


\begin{tabular}{|c|c|c|c|}
\hline Sodium (mmol/L) & $141(140 ; 143)$ & $138(136 ; 140)$ & $<0.001$ \\
\hline Potassium (mmol/L) & $3.9(3.7 ; 4.2)$ & $4.2(3.9 ; 4.6)$ & $<0.001$ \\
\hline Copeptin (pmol/L) & $14(9 ; 21)$ & $28(18 ; 45)$ & $<0.001$ \\
\hline Suppression of Tumorigenicity 2 (ng/mL) & $23(16 ; 30)$ & $35(23 ; 51)$ & $<0.001$ \\
\hline \multirow[t]{2}{*}{ Galectin-3 (ng/mL) } & $17(13 ; 21)$ & $17(13 ; 22)$ & 0.913 \\
\hline & & 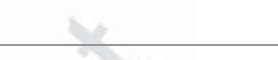 & \\
\hline Glucose fasting (mmol/L) & $5.6(5.1 ; 7.5)$ & $5.5(4.9 ; 6.9)$ & 0.127 \\
\hline Insulin ( $\mu \mathrm{U} / \mathrm{ml})$ & $11(8 ; 17)$ & $11(7 ; 17)$ & 0.642 \\
\hline Homeostatic Model Assessment-Insulin Resistance & $3.4(2.0 ; 5.6)$ & $2.6(1.3 ; 5.3)$ & 0.237 \\
\hline Adiponectin (mg/L) & $12(8 ; 20)$ & $14(7 ; 21)$ & 0.471 \\
\hline Leptin (ng/L) & $24(12 ; 52)$ & $15(6 ; 33)$ & 0.015 \\
\hline Insulin-like Growth Factor 1 (mikrog/L) & $174(137 ; 206)$ & $149(105 ; 219)$ & 0.101 \\
\hline SD score Insulin-like Growth Factor 1 & $1.22(0.62 ; 1.93)$ & $0.09(-1.40 ; 1.62)$ & $<0.001$ \\
\hline $\begin{array}{l}\text { Insulin-like Growth Factor Binding Protein } 1 \\
\text { (mikrog/L) }\end{array}$ & $48(28 ; 78)$ & $65(29 ; 101)$ & 0.074 \\
\hline
\end{tabular}


Table 2. Correlations between IGFBP-7 and clinical characteristics and biomarkers in HFpEF and HFrEF patients.

\begin{tabular}{|c|c|c|c|c|c|c|c|c|}
\hline \multirow[b]{2}{*}{$\begin{array}{l}\text { IGFBP-7 ug/L } \\
\text { in HFpEF }\end{array}$} & \multicolumn{4}{|c|}{ HFpEF $(n=86)$} & \multicolumn{4}{|c|}{ HFrEF $(n=79)$} \\
\hline & Rho & p-value & $\begin{array}{l}\text { Standardized } \\
\beta \text { - } \\
\text { Coefficient* }\end{array}$ & p-value & Rho & p-value & $\begin{array}{l}\text { Standardized } \\
\beta \text { - } \\
\text { Coefficient* }\end{array}$ & p-value \\
\hline Women & 0.032 & 0.771 & -0.308 & 0.069 & -0.177 & 0.119 & -0.710 & 0.014 \\
\hline Age & 0.148 & 0.174 & $0.064 * *$ & 0.475 & 0.292 & 0.009 & $0.046 * *$ & 0.664 \\
\hline $\begin{array}{l}\text { Systolic blood } \\
\text { pressure }\end{array}$ & 0.046 & 0.677 & 0.113 & 0.204 & 0.017 & 0.889 & 0.077 & 0.454 \\
\hline $\begin{array}{l}\text { Diastolic blood } \\
\text { pressure }\end{array}$ & -0.114 & 0.296 & -0.025 & 0.786 & -0.038 & 0.753 & 0.032 & 0.752 \\
\hline Heart rate & 0.038 & 0.726 & -0.024 & 0.795 & 0.354 & 0.001 & 0.198 & 0.048 \\
\hline Body Mass Index & 0.103 & 0.343 & 0.132 & 0.151 & -0.126 & 0.268 & -0.051 & 0.636 \\
\hline NYHA & 0.250 & 0.020 & & 0.326 & 0.258 & 0.022 & & 0.574 \\
\hline
\end{tabular}

\begin{tabular}{|c|c|c|c|c|c|c|c|c|}
\hline Hypertension & 0.047 & 0.666 & -0.074 & 0.716 & & & & \\
\hline Atrial fibrillation & 0.103 & 0.343 & -0.020 & 0.908 & 0.340 & 0.002 & 0.194 & 0.294 \\
\hline $\begin{array}{l}\text { Chronic } \\
\text { Obstructive } \\
\text { Pulmonary } \\
\text { Disease }\end{array}$ & 0.044 & 0.687 & 0.093 & 0.630 & 0.075 & 0.511 & -0.360 & 0.224 \\
\hline $\begin{array}{l}\text { Diabetes mellitus } \\
\text { type } 2\end{array}$ & 0.108 & 0.323 & 0.408 & 0.029 & 0.060 & 0.597 & 0.165 & 0.384 \\
\hline Cancer & 0.217 & 0.045 & 0.496 & 0.041 & -0.025 & 0.824 & -0.025 & 0.925 \\
\hline $\begin{array}{l}\text { estimated } \\
\text { Glomerular } \\
\text { Filtration Rate }\end{array}$ & -0.465 & $<0.001$ & $-0.365 * * *$ & 0.001 & -0.451 & $<0.001$ & -0.302 & $0.008^{* * *}$ \\
\hline $\begin{array}{l}\text { N-terminal pro- } \\
\text { brain natriuretic } \\
\text { peptide }\end{array}$ & 0.525 & $<0.001$ & 0.409 & $<0.001$ & 0.503 & $<0.001$ & 0.396 & 0.001 \\
\hline
\end{tabular}




\begin{tabular}{llllllllll} 
Glucose & 0.006 & 0.9591 & 0.191 & 0.032 & 0.187 & 0.141 & 0.110 & 0.310 \\
\hline Homeostatic & 0.001 & 0.993 & 0.030 & 0.738 & -0.011 & 0.933 & 0.002 & 0.986
\end{tabular}

Model

Assessment-

Insulin Resistance

\begin{tabular}{|c|c|c|c|c|c|c|c|c|}
\hline Hemoglobin & -0.298 & 0.005 & -0.278 & 0.003 & -0.182 & 0.110 & -0.097 & 0.319 \\
\hline Copeptin & 0.441 & $<0.001$ & 0.203 & 0.057 & 0.461 & 0.001 & 0.287 & 0.067 \\
\hline $\begin{array}{l}\text { Suppression of } \\
\text { Tumorigenicity } 2\end{array}$ & 0.507 & $<0.001$ & 0.360 & $<0.001$ & 0.546 & $<0.001$ & 0.376 & $<0.001$ \\
\hline Galectin-3 & 0.375 & $<0.001$ & 0.134 & 0.287 & 0.577 & $<0.001$ & 0.456 & $<0.001$ \\
\hline $\begin{array}{l}\text { MR-pro- } \\
\text { adrenomedullin }\end{array}$ & 0.572 & $<0.001$ & 0.365 & 0.003 & 0.843 & $<0.001$ & 0.977 & $<0.001$ \\
\hline $\begin{array}{l}\text { MR-pro-atrial } \\
\text { natriuretic } \\
\text { peptide }\end{array}$ & 0.550 & $<0.001$ & 0.351 & 0.042 & 0.301 & 0.044 & -0.050 & 0.766 \\
\hline Adiponectin & -0.013 & 0.905 & -0.094 & 0.324 & 0.352 & 0.002 & 0.141 & 0.188 \\
\hline Leptin & 0.222 & 0.042 & $-0.072 * * * *$ & 0.519 & -0.319 & 0.004 & $-0.382 * * * *$ & $<0.001$ \\
\hline $\begin{array}{l}\text { Insulin-like } \\
\text { Growth Factor } 1\end{array}$ & -0.042 & 0.700 & -0.175 & 0.053 & -0.268 & 0.017 & -0.165 & 0.089 \\
\hline $\begin{array}{l}\text { SD score Insulin- } \\
\text { like Growth } \\
\text { Factor } 1\end{array}$ & -0.011 & 0.920 & $-0.152 * *$ & 0.123 & -0.186 & 0.101 & $-0.019 * *$ & 0.897 \\
\hline $\begin{array}{l}\text { Insulin-like } \\
\text { Growth Factor } \\
\text { Binding Protein } 1\end{array}$ & 0.304 & 0.005 & 0.118 & 0.234 & 0.688 & $<0.001$ & 0.448 & $<0.001$ \\
\hline Insulin & -0.016 & 0.887 & -0.055 & 0.544 & -0.150 & 0.194 & -0.072 & 0.476 \\
\hline
\end{tabular}

* Adjusted age, eGFR, NT-proBNP

** Adjusted eGFR, NT-proBNP

*** Adjusted age, NT-proBNP

****Adjusted age, eGFR, NT-proBNP, weight 
Table 3. Correlations between IGFBP-7 and ECHO measurements in HFpEF patients IGFBP-7 ug/L in HFpEF

\begin{tabular}{|c|c|c|c|c|}
\hline & Rho & p-value & $\begin{array}{l}\text { Standardized } \\
\beta \text {-Coefficient* }\end{array}$ & p-value \\
\hline Stroke volume & -0.045 & 0.781 & & \\
\hline Left ventricular ejection fraction (biplane) & 0.002 & 0.988 & & \\
\hline Left ventricular end diastolic volume indexed (LVEDVI) & -0.020 & 0.910 & & \\
\hline Left ventricular end systolic volume indexed (LVESVI) & -0.074 & 0.667 & & \\
\hline Left ventricular mass index (LVMI) & -0.234 & 0.169 & & \\
\hline Inter ventricular septal thickness & -0.028 & 0.820 & & \\
\hline Posterior wall thickness in diastole & 0.114 & 0.358 & 8 & \\
\hline Left ventricular outflow tract diameter (LVOT) & -0.043 & 0.718 & & \\
\hline Velocity time integral of the flow in the LVOT & 0.067 & 0.570 & & \\
\hline Left atrial diameter & 0.134 & 0.286 & & \\
\hline Left atrial volume index & 0.140 & 0.417 & & \\
\hline Right ventricle diameter & 0.141 & 0.314 & & \\
\hline Right ventricular end-diastolic area & 0.275 & 0.032 & 0.362 & 0.011 \\
\hline Right ventricular end-systolic area & 0.245 & 0.055 & & \\
\hline Right ventricular shortening & -0.070 & 0.591 & & \\
\hline Tricuspid annulus plan systolic excursion (TAPSE) & -0.158 & 0.173 & & \\
\hline Isovolumic relaxation time & -0.287 & 0.011 & 0.107 & 0.525 \\
\hline Interventricular time delay & 0.190 & 0.099 & & \\
\hline E/A ratio & 0.334 & 0.011 & 0.291 & 0.062 \\
\hline $\mathbf{E}^{\prime}$ & -0.023 & 0.084 & & \\
\hline 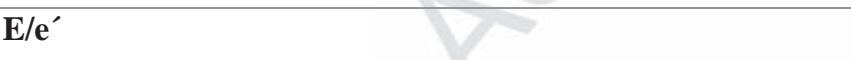 & 0.310 & 0.012 & 0.405 & 0.007 \\
\hline 2D strain, mean peak of $L V$ deformation /16 LV segments & -0.010 & 0.936 & & \\
\hline 2D global strain apical 4 chamber view & -0.007 & 0.955 & & \\
\hline Global longitudinal strain of the right ventricle & 0.250 & 0.209 & & \\
\hline
\end{tabular}




\section{SUPPLEMENTARY MATERIAL}

Table. Baseline characteristics in the 22 LVAD and 34 HTx patients. Continuous variables are presented as median and interquartile range (lower and upper quartiles; Q1;Q3) and categorical variables as numbers (n) and \% when not otherwise stated. 


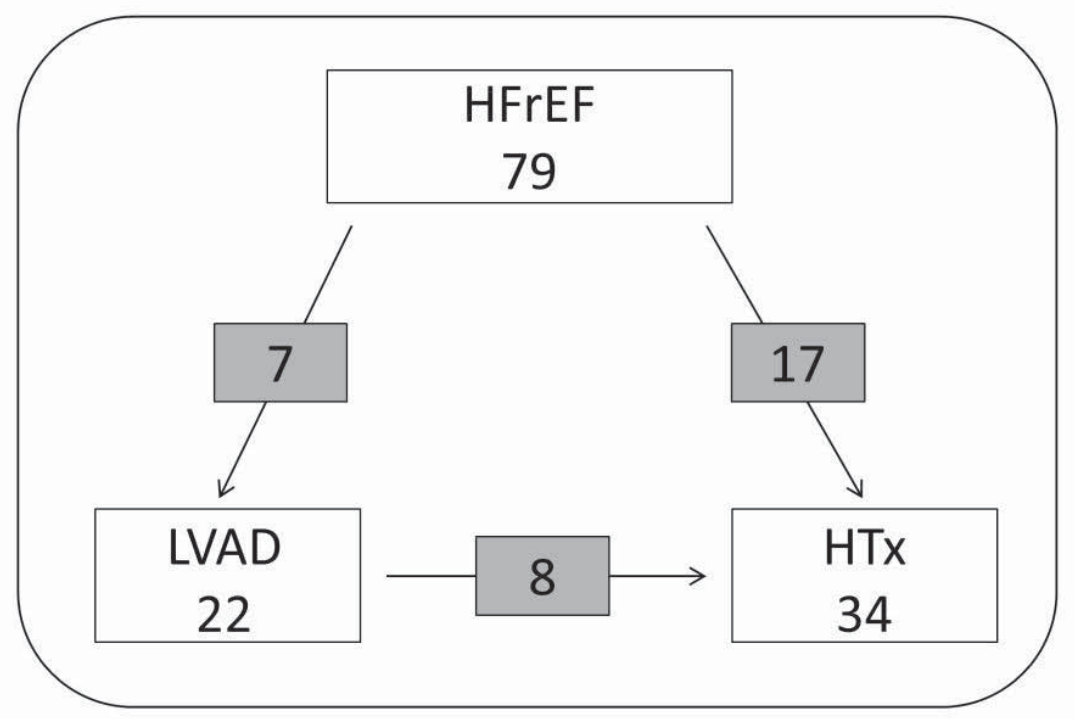

Figure 1.tif 


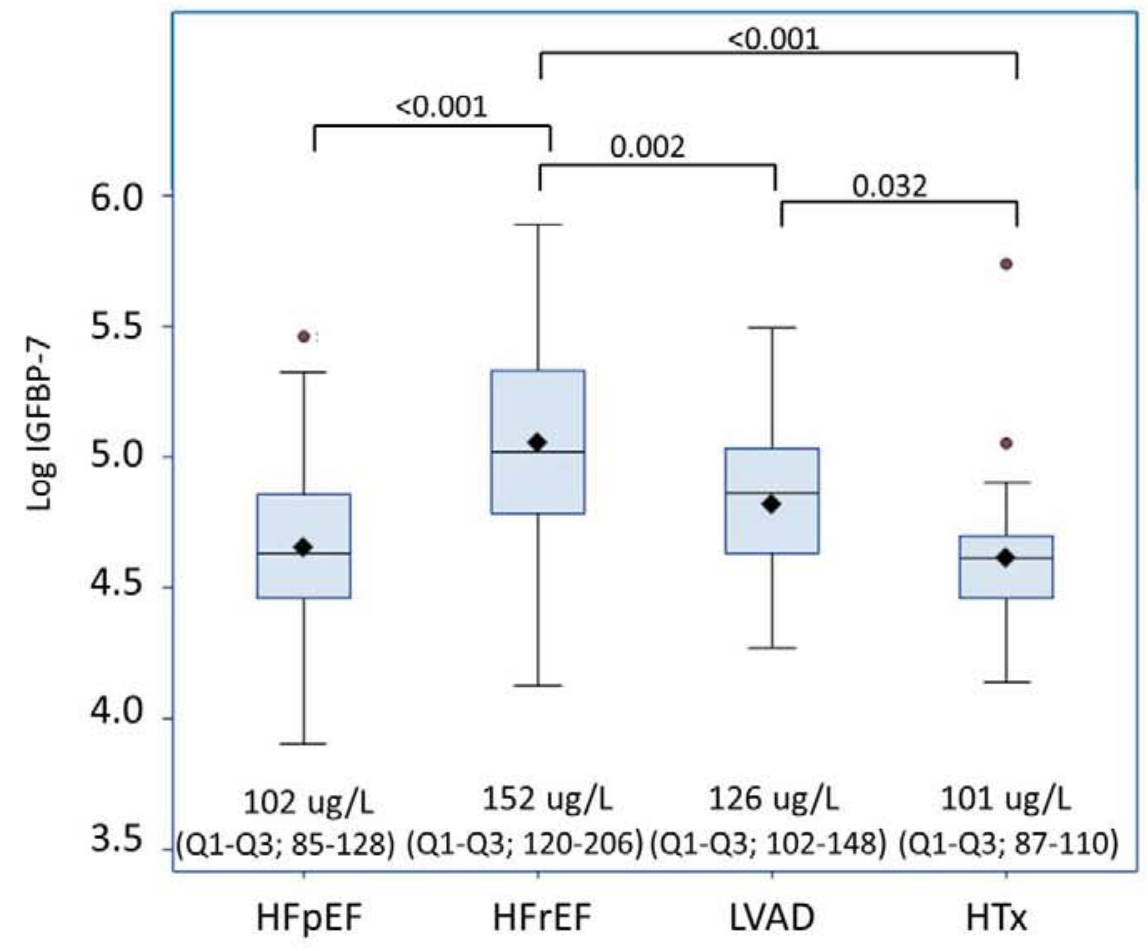


Figure 2.TIF 

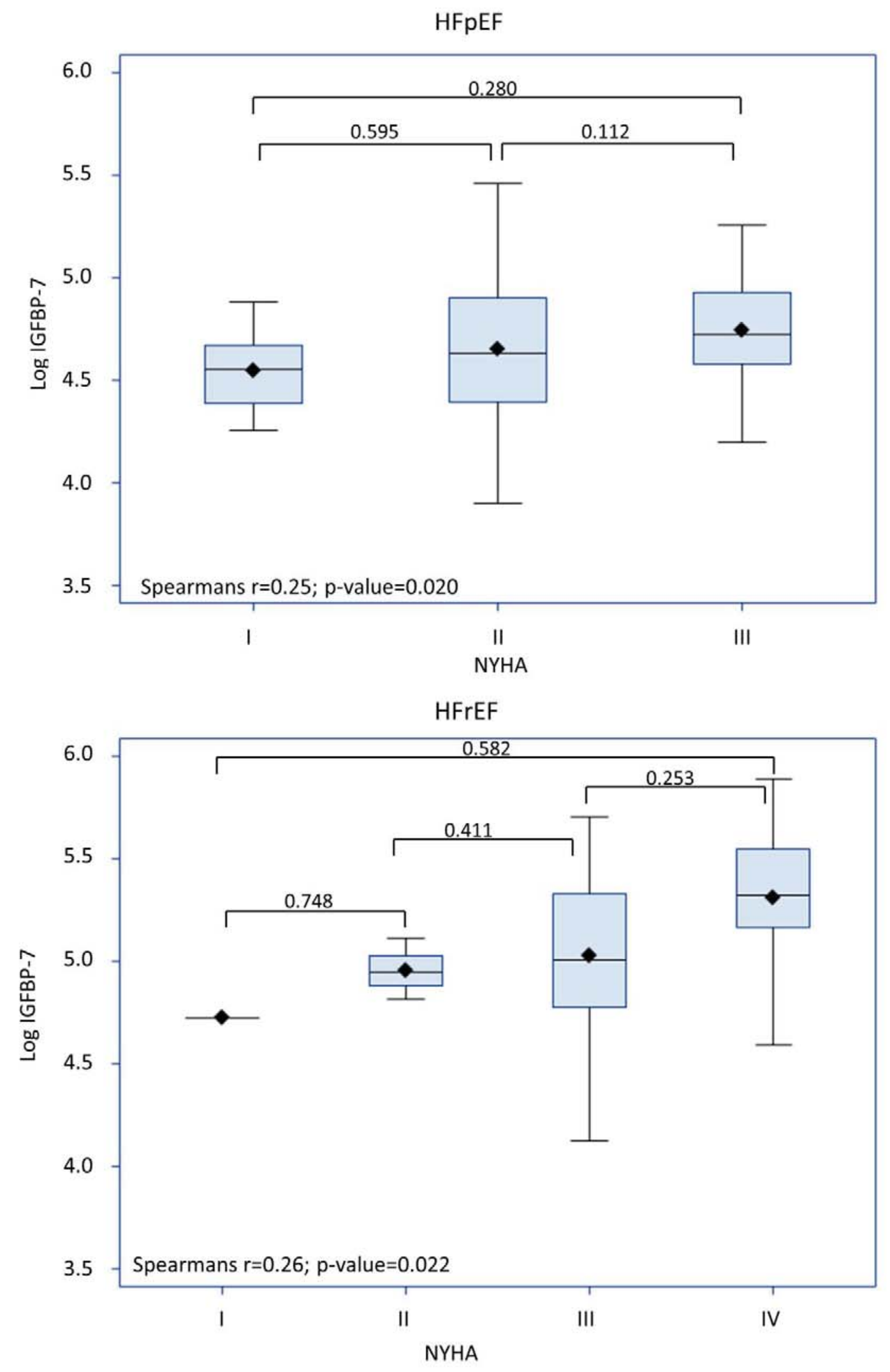
Figure 3.tif 
HFpEF

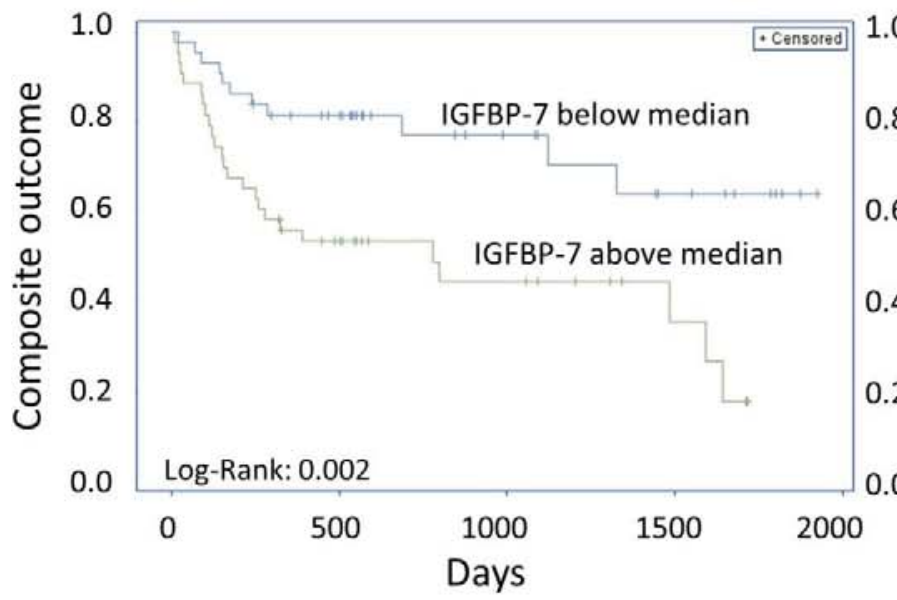

HFrEF

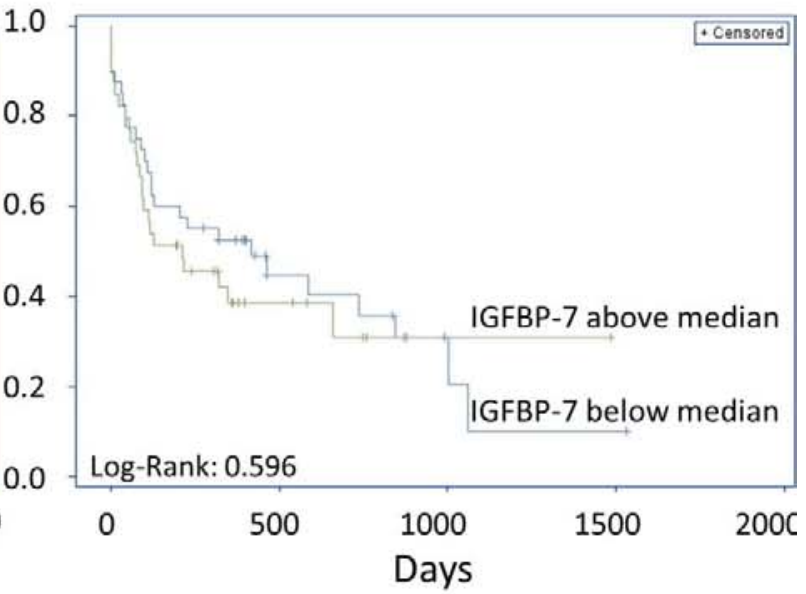

\begin{tabular}{|c|c|c|c|c|c|c|}
\hline \multirow[t]{2}{*}{ Variable } & \multicolumn{3}{|c|}{$\begin{array}{l}\text { HFpEF } \\
\text { All-cause mortality or HF } \\
\text { hospitalization }(n=36)\end{array}$} & \multicolumn{3}{|c|}{$\begin{array}{l}\text { HFrEF } \\
\text { All-cause mortality, LVAD or HTx }(n=50)\end{array}$} \\
\hline & $\begin{array}{l}\text { Hazard ratio } \\
\text { (per log } \\
\text { increase) }\end{array}$ & $95 \% \mathrm{Cl}$ & $\mathrm{p}$-value & $\begin{array}{l}\text { Hazard ratio } \\
\text { (per log } \\
\text { increase) }\end{array}$ & $95 \% \mathrm{Cl}$ & $p$-value \\
\hline IGFBP-7 & 4.29 & $\begin{array}{l}1.44- \\
12.78\end{array}$ & 0.009 & 1.39 & $0.61-3.14$ & 0.433 \\
\hline IGFBP-7(adjusted eGFR) & 5.52 & $\begin{array}{l}1.49- \\
20.48\end{array}$ & 0.011 & 1.37 & $0.54-3.46$ & 0.506 \\
\hline IGFBP-7(adjusted age) & 4.48 & $\begin{array}{l}1.50- \\
13.38\end{array}$ & 0.007 & 1.59 & $0.68-3.69$ & 0.285 \\
\hline IGFBP-7(adjusted gender) & 4.27 & $\begin{array}{l}1.42- \\
12.87\end{array}$ & 0.010 & 1.37 & $0.60-3.13$ & 0.457 \\
\hline IGFBP-7(adjusted NT-proBNP) & 2.95 & $\begin{array}{l}0.86- \\
10.10\end{array}$ & 0.086 & 0.63 & $0.24-1.67$ & 0.351 \\
\hline $\begin{array}{l}\text { IGFBP-7(adjusted eGFR, age, } \\
\text { gender and NT-proBNP) }\end{array}$ & 4.19 & $\begin{array}{l}1.01- \\
17.35\end{array}$ & 0.048 & 0.72 & $0.24-2.14$ & 0.554 \\
\hline
\end{tabular}


Figure 4.TIF 